\title{
An Analysis of Multimodal Text in EFL Textbook of Secondary School in Indonesia in Assisting Students' Text Understanding
}

\author{
Weny Fitriana, ${ }^{*}$ Yanty Wirza \\ English Language Study Program, Universitas Pendidikan Indonesia, Bandung \\ *Corresponding author. Email: wenyfitriana@upi.edu
}

\begin{abstract}
The existence of images in the textbook has brought many benefits to the EFL Classroom. The research on multimodality in EFL textbooks has been largely conducted. However, there is a lack of research that focuses on the textbook's verbal and visual elements. Therefore, this study aims to analyze the aspects of verbal and visual elements in the textbook and analyze the visual element's role in understanding the verbal component. The data of multimodal elements found is taken from the textbook Pathway to English verbal and visual data and the textbook user. The selected data are taken from the text presented along with the images. The qualitative method of the research proposed by Miles and Huberman was involved in this study. The multimodal framework, a combination of Halliday's Systemic Functional Linguistic and Kress and Van Leeuwen's Grammar Visual Design, identifies the multimodal elements that appear in the textbook and analyze whether the images presented help the learner in understanding the text. This study reveals the ideational functions of the verbal elements and three patterns of visual elements. The visual elements presented also give pedagogical benefits to students in understanding the text. However, the textbook analysis of the visual image and the teacher and students' responses show that there should be an improvement in the visual elements' color and size.
\end{abstract}

Keywords: Ideational function, multimodality, visual grammar design

\section{INTRODUCTION}

Cognitive studies have revealed a relationship between multimodality and learning since the $1970 \mathrm{~s}$ (Liu \& Qu, 2014). Textbooks' multimodality, especially that of language textbooks in the educational field, is regarded as closely related to teaching effectiveness and efficiency. In terms of multimodality textbook evaluation, one study found that learners' meaningmaking tends to be heavily guided and that images and texts seem to foster mainly linguistic competence (Weninger \& Kiss, 2013). Besides, the focus of multimodality on the text, including verbal and images which based on Leeuwen's and Halliday's framework, show that the teachers

Lack of critical awareness of language study and multimodality. The multimodal text analyses can be used to improve their teaching activity, particularly to develop their own and students' critical language awareness and multimodality (Nguyen, 2011). Concerning the students reading, a study was conducted by Callow (2006) and Walsh (2003) (cited in Januarty \& Azizah Nima, 2018). It is stated that using multimodal texts contributes to students' cognitive skills and increases their creativity, attention, participation production, and changes in reading and writing. Analyze the multimodality can also be used to identify the textbook's potential meaning, further the intention of the publisher (Torres, 2015).

Reflecting on those previous research, Systemic Functional Grammar theory of Halliday and Visual Grammar (VGA) by Kress theory is combined in this research. Those theories are combined with knowing whether students benefit from the multimodal text in their reading or no. In this study, as the focus will be on the multimodal texts (those presented with pictures), the 'meaning potential' will be analyzed using verbal and visual analysis. The verbal mode of this framework includes ideational, interpersonal, and textual functions. This theory is adopted from Halliday's theoretical notion of a metafunction. The ideational meanings are based on 
investigating 'narrative and conceptual representation' (Kress \& Leeuwen 2006). Even though the study of multimodality involves analyzing interpersonal meaning textual meaning, the researcher will focus only on the experiential function that belongs to the ideational function. To analyze the visual mode, the researcher adopts GVD by Kress and Leeuwen (2006) based on the three patterns: Representation, which focuses on the participant. Besides gaze, frame, and angel, which under the term of interaction function and composition, which includes informative value, salience, and framing, that might occur in an image.

The emphasis on the images' meaning potential if we want to treat forms of communication employing images as seriously as linguistic forms have been, analyzing visual communication is an important part of critical discipline (Kress \& Leeuwen, 2006). Besides, the whole text's meaning could be scrutinized through different modes' and possible inter-semiotic relationships. This research will analyze the students' perspective on the multimodal text. The issue raised is whether the picture presented with the text helps them engage in the reading task. Analysis in the context of the textbook is not enough. It should involve practical benefits to both students and teachers, one of which is how textbooks direct or guide students' engagement with knowledge can critique pedagogy as ideological practice (Weninger, 2020). However, there is less research conducted on the multimodality of the Indonesian EFL textbook.

This study intended to analyze the textbook's verbal and visual elements and evaluate whether images in that book carried out a pedagogical role in assisting students in comprehending the text. Employing Halliday's systemic functional linguistic on ideational meaning to analyze the verbal elements grammar visual design framework in analyzing the textbook's visual images, this study is intended to give insight into visual images' appropriateness for pedagogical purposes.

\subsection{Social Semiotic}

A field that investigates human practices in particular social and cultural circumstances and understands meaning-making as a social practice can be understood as a social semiotic. Signs are the fundamental concept of semiotics, termed semiotic resources in semiotics. The semiotic resources are not restricted to speech and writing and picture-making. "Almost everything we do or make can be done or made in different ways, allowing, at least in principle, to articulate different social and cultural meanings" (Van Leeuwen, 2005: 4). Social semiotic focus on social meaning-making practices of all types, whether visual, verbal, or aural. These all are also known as semiotic modes. The same term of modes is also used in describing multimodal. According to Halliday (1978), languages evolve as systems of meaning potential or assets of resources that affect what the speaker can do with language in a given social context (p.39). For instance, the English language's grammar is a system organized for three purposes (metafunctions).

Social semiotics are late expanding this common system by going advance than linguistic due to the developing significance of sound and visual pictures and how communication modes are combined in either conventional and computerized media. Leeuwen has built on Halliday's theory by giving new language structures for other semiotic modes. These linguistic uses are seen as socially shaped and changeable sets of accessible resources, making meaning formed by the semiotic metafunctions initially recognized by Halliday.

\subsection{Ideational Function}

Ideational functions cover the area of phenomena about things (living and non-living, abstract and concrete), about going on (what the things are or do), and the circumstances surrounding these happenings and doings. Ideational functions are influenced by the field of discourse about the text's topic, making the clauses as representations (Hallidey, 1978). The ideational functions include the experiential function and logical function. Participants include the people or entities that take part in the process. Processes realized as verbs link participants. Participants presented in an active role as the doer 'of an action, the experiencer 'or sense 'of a state or feeling, the sayer 'of something, and the carrier 'of an attribute. Participants in passive roles can be someone or something impacted by, affected by, done to 'or receiver 'of the processes - the changing labels of participants occur when the process involved changes. Another element is Circumstances, which answer when, where, why, how of the process involved in the text. Accompaniment tells the circumstances regarding with or without someone or something.

\subsection{Visual Grammar}

According to Leeuwen and Kress, visual grammar, images can fulfill Halliday's three major functions through the following patterns: Patterns of representation, interaction, and composition (Kress \& Leeuwen, 2006). The pattern of representation refers to the visual resources for representing interaction and conceptual relations between the people, places, and things depicted in the image and correspond to Halliday's 'ideational' metafunction. Patterns of interaction are by Halliday's interpersonal metafunction and refer to the resources, which construct a relationship between the image producer and the people represented in the image and the viewer. And patterns of composition refer to how patterns of representation and interaction cohere into meaningful wholes that also 
correspond to Halliday's textual meta-function. The elements in the visual images realize all these patterns. Some elements are related to specific patterns.

\section{METHOD}

\subsection{Research Design}

A descriptive qualitative method was employed as the research method. As Monsen, E.R.\& Horn (2008) stated, "descriptive qualitative is an effective way to gain information used in planning hypotheses and suggesting association" (p.5). The data analysis includes coding, data reduction, and interpretation (Miles \& Huberman, 2014). This method was in line with this research because, in this research, the data were collected, categorized, and analyzed. Then, in the last process, the data were made to interpret several texts used by teachers in the class.

\subsection{Participants}

This research was conducted at the Vocational school of Kesuma Margoyoso. Sixty-two participants come from the students, and eight come from the teacher response. Document collection, questionnaire, and interview are involved as the data collection technique. The Pathway to English textbooks as the main subject was analyzed while the data gathered from the students and teacher were only to know their perspective in using the book.

\subsection{Data Collection and Analysis}

Document analysis requires data to be examined and interpreted to elicit meaning, gain understanding, and develop knowledge (Corbin\&Strauss, 2008 as cited in Bowen, 2009). The document was collected from the chosen textbook, mainly the images along with the reading passages. The second data were collected through interviews and questionnaires. While the questionnaire is addressed to both teachers and students, an interview is only conducted with the teacher. In analyzing data, the data were divided into two steps. First, the textbook is analyzed in the images and the passages presented using the theory from Halliday (1978) and Kress and Leuween (2006). And the result of the interview and questionnaire were analyzed by supporting the theory that images can support the text's comprehension.

\section{FINDINGS AND DISCUSSION}

\subsection{Findings}

\subsubsection{Verbal and Visual Element of Textbook}

After examining the textbook, the textbook consists of two modes, verbal and visual. Verbal elements are the reading passage, while the visual element is the picture presented along with the picture. The verbal elements are analyzed with one of the metafunction theory from Hallyday that is an experiential function to determine the process, participants, and circumstances. Besides, the visual elements are identified based on their patterns of images that create meaning.

The verbal process element in this textbook includes process, participants, and circumstances under the ideational function of Halliday systemic functional linguistic. The process found is a mental, material, relational, behavioral, verbal, and existential process. The dominant process is the relational process, $42 \%$, and the material process of $22 \%$. The textbook participant consists of participants in the mental process, with $37.5 \%$ and the most dominant phenomena, $62.5 \%$. The relational process participants include relational identifying and relational attributive processes, which have the same proportion, 50\%, respectively. The participant in the behavioral process consists of only a behaver. The participant in the verbal process includes behaver with $62.5 \%$ and verbiage with $37.5 \%$. And the participant in the existential process found is existent.

While the visual elements found are the pattern of representation, the pattern of interaction, and composition pattern, which is further discussed in Figure 1.

The image presented enables the student to identify the main characters, the way they interact with each other, and the circumstances. The three main characters, interactive participants, are depicted in a specific social context, which seems to be an office. The students can infer this by analyzing the representation as it only focuses on three people and no other background participant. The participants are standing up and looking at each other, and their gestures, represented mainly by their arms and facial expressions, show they are actively involved in a conversation.

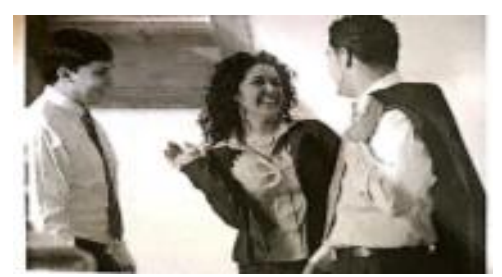

Figure 1 Image from a conversation in the Pathway to English: Hi, My Name Is. Source: Pathway to English. (2016, p. 9) 
Analyzing the representational structure of the image and considering only the woman and the man on the right side of the picture, it is accurate to state that they indicate a transactional reaction - a vector emanates from the man's eyes toward the woman's eyes and vice versa. Their arms also form vectors toward each other since they laugh at each other, which may indicate that they are being made a good talk to each other. Another vector emanates from the man's eyes on the left side of the image toward the man and the woman on the right side of the image. Furthermore, the right arm of the woman on the left smiles at the man on the right, forming a vector that suggests she is introducing the man on the right side to the man, and the gesture of hand indicates that the woman is about to leave. Therefore, his utterance "By the way, my name is Jack Sammorse", please call me Jack. I am from Toronto, Canada" "Nice to meet you, Jack. I am Rosiana Simatupang. Just call me Rosy." confirms this interpretation. Looking at the participants' attributes can also assist viewers to understand who these participants are and what actions they are involved in. The main participants seem to be young adults (maybe a worker) due to the casual clothes and what seems to be a suit the woman is holding. Therefore, the sentence "Well, I am a TV presenter" in the dialogue confirms this interpretation. The image also fulfills the interactive meaning as this image gives the relationship between the viewers and the image.

Image 1 represents an offer since none of the participants depicted is directed to the viewer, demanding an "answer" or reaction from the reader. From these images, we see that the image 'offers' the represented participants to the viewer as information objects, objects of contemplation, impersonally. The viewers are not intended to participate in the conversation since they only observe the scene (a narrative, in GVD's term) as if it were a movie as presented in this image.

The images presented also contain the compositional aspect. Both the man on the left side and the woman are "given"; they are together, placed on the same oblique angle and interacting with the new participant, the man on the image's left side. Thus, the position of the participants in the image and the act of "smiling each other" can help EFL students to realize that the conversation began between the man and the woman on the right, and the man on the left arrived later, and the women leave them to talk.

Salience is also found as the compositional aspect in the image, represented through the participants' location in the foreground (medium shot), composing the setting and contextualizing the narrative. Besides being represented in a medium shot, which provides them with more visibility in the scene, the main participants are portrayed in black and white, however making it less attractive. Thus, viewers may realize that the conversation's focus concentrates on the three people in the foreground, and the picture does not present other participants. The visual analysis of Image 1 as the sample shows that the interpretation of the picture supported by the three metafunctions proposed by Kress and Leuween (2006) may help students to understand the written text.

\subsubsection{Students and Teacher Perception toward the Picture Presented and the Text to Assist the Understanding of the Reading Passage.}

This research involves seventy participants in the Vocational school of Kesuma Maryoso. Sixty-two comes from the students, and eight comes from the teacher response. The questionnaire is divided into three categories. The first category is whether the picture presented helps the students to understand the text. The second relates to whether the picture presented is attracting them to read the text. And the last question is what should be improved of the picture presented. For the first and second cases, the students' responses are positive toward the images presented as it helps them to get the gist of the text, and the images presented are fairly attractive.

The next response is about the students' and teachers' perceptions of what should be refined in the picture. The researcher provides four choices of the aspect that should be improved: color and sharpness, size, color, and size, and the last is the position of the picture in the book. Table 1 shows the result of the responses.

The result of the questionnaire that the images give pedagogical benefit is also confirmed with the interview result. The result of the interview shows that the presented images bring educational benefit to understand the passages. The teacher has used this book for two years in the tenth grade of vocational school. The images are presented in almost every student's task and the reading passage. The teacher said that the book helps the students understand the text, mainly in building the context.

Table 1. Students' \& teachers' response of the picture improvement

$\begin{array}{cccc}\begin{array}{c}\text { Colour and } \\ \text { sharpness }\end{array} & \begin{array}{c}\text { Size and } \\ \text { framing }\end{array} & \begin{array}{c}\text { Colour } \\ \text { and size }\end{array} & \begin{array}{c}\text { Picture's } \\ \text { position }\end{array}\end{array}$
$31 \%$
$6.8 \%$
$52.1 \%$
$14.1 \%$ 
"I ask my students to look at the picture that is presented with the text; then I asked them to guess what the text is going to discuss. It helps them to build the context of the text. for example, in chapter 1, three people have a conversation in the office, so my students will know that the dialogue will be talking about business."

Besides, the book's color has a crucial role in attracting students' interest in reading the text. Even it is commonly needed for the young learner, but the adult learner from this vocational school also stated that the more colorful image attracts them.

"The images should be colorful, even me as the teacher will attract more to the text when the images have full colors, and it also can attract students interest in reading the text, besides it won't make students bored."

An interview can be concluded that the teacher is aware of the need for high-level multimodality in the textbook. It is a means to attract students' attention and interest. Furthermore, the students will improve their willingness to learn English with the textbook. The result of the questionnaire and interview with the teacher proves that images play an important role in attracting students' interest and attention to the text in the educational context. It proves that images genuinely benefit students in attracting students and easing students to comprehend the context of the passages presented.

\subsection{Discussion}

The analysis of the verbal and visual elements of the Pathway to English textbook has brought some conclusions. This analysis focuses on the verbal aspects of the reading passage using the ideational meaning of Hallidey's (1978) and Leeuwun (2006) in analyzing the visual element.

The findings show that the verbal element has fulfilled the criteria of good text in terms of ideational meaning proposed by Hallidey (1978). Text is a language instrument that is functional in its context. It is necessary to provide its clear meaning (Simaibang, 2011) by involving the text's ideational meaning. As the material process is the most dominant, it shows that the students understood the text as comprising explicit physical action of what happened and what is done (Halliday, 1978). While the dominant relational process indicates that the students can describe the condition that happened in the text so that they are easier in understanding the text.

The visual analysis of images extracted from the Pathway to English showed that the three metafunctions proposed by Kress and Leeuwen (2006) support the interpretation of the image. Leeuwen (2005) includes representational, interactional, and compositional meaning is in a position to assist the students in comprehending the transcription or written conversation supported by the provided images. Several clues like the act of shaking hands, countenance, participants' gaze at the position of the characters within the picture provide evidence that will contribute to students' understanding of the textual content provided within the image. The questionnaire and interview result shows that the images presented along with the text bring pedagogical benefit for students in understanding the passage. Mainly, it assists students in building the context before they read the text. This finding is supported by (Moghtadi, 2013) stated that visual materials draw the possibilities to enhance language learning as it functions as communication tools and influential elements in constructing students' knowledge related to the real world.

The finding shows that the images bring pedagogical benefit to the student in interpreting the text. In broader benefit, images stimulate students' interest and encourage them to learn the language in a more reactive way, building students' attention and knowledge, reducing cognitive load, and motivating students to learn and relate students to learn materials in a meaningful way (Yazdanmehr \& Shoghi, 2014). However, the composition and salience pattern in terms of color and sharpness is minus as the picture presented is only black and white. Colour and sharpness are essential to attract students' attention to go further in the text (Olurinola \& Tayo, 2015).

\section{CONCLUSION}

First, the English textbook text in Chapters 1-8 consists of six process types. The dominant process is the relational process, $42 \%$, and the material process of $22 \%$. The conceptual meaning characterized in the Pathway to the English textbook in chapters 1-8 meets the good text to be understandable. The relational and material process was dominant because, presumably, texts under analysis belong to a procedural genre that heavily draws on the material processes. It is stated that "the material clauses construe the procedure as a sequence of concrete changes" (Hallidey 2004, p. 179). In comparison, the Relational is dominant as it appears as information.

Second, the images' analysis has fulfilled the theory proposed by Leuween, which includes a pattern of representation, the pattern of interaction, and composition pattern. The act of shaking hands, countenance, participants' gaze at the position of the characters within the picture provide evidence that will contribute to students' understanding of the textual content provided within the image. It is also supported by the questionnaire and interview result, which shows that the images presented and the text brings 
pedagogical benefit for students in understanding the passage.

However, there is a lack of composition pattern, mainly in terms of the picture's color and size. There should be an improvement. More colorful images will attract students to read the reading passage rather than the monochrome images. Therefore, this study may give the textbook maker new consideration to improve the Pathway to English Textbook's multimodality, particularly in the images presented. So that the motivation of students to learn English by using this textbook increases, and it will affect the learning outcome.

\section{REFERENCES}

Bowen, G. A. (2009). Document analysis as a qualitative research method. Qualitative Research Journal, $9(2), \quad 27-40$. https://doi.org/10.3316/QRJ0902027

Kress, G., \& Leeuwen, T. . (2006). Reading images: The grammar of visual design. London: Routledge.

Halliday, M. A. K. (1978). Language as Social Semiotic: The Social Interpretation of Language and Meaning. Baltimore: University Park Press.

Halliday, M. A. K., \& Matthiessen, C. M. I. M. (2004). An introduction to functional grammar. London: Arnold.

Januarty, R.-, \& Azizah Nima, H. N. (2018). Energising Students' Reading Comprehension Through Multimodal Texts. International Journal of Language Education, 2(2), 14-22. https://doi.org/10.26858/ijole.v2i2.4347

Liu, X., \& Qu, D. (2014). Exploring the multimodality of EFL textbooks for Chinese college students: A comparative study. RELC Journal, 45(2), 135-150. https://doi.org/10.1177/0033688214533865

Miles, M. B., \& Huberman, A. M.. (2014). Qualitative Data Analysis 3rd Edition. London: Sage Publications.

Moghtadi, L. (2013). Visual elements used in Iran EFL high school textbooks. International Journal of Foreign Language Teaching and Research, 1(1), 45-56.
Monsen, E.R.,Van, H.L., \& American Dietetic Association. (2008). Research: Successful approaches. Chicago: American Dietetic Association.

Nguyen, T. T. (2011). An Analysis of Multimodal texts in the EFL textbooks for secondary schools in Vietnam From Teachers' Perspectives on Raising Critical Language Awareness: A Multimodal Approach. Dissertation. London: London Metropolitan University. Retrieved from https://www.academia.edu/4028781/MA_thesis_A n_analysis_of_multimodal_text_in_EFL_textbooks _to_raise_critical_language_awareness_A_multim odal_approach

Olurinola, O., \& Tayo, O. (2015). Colour in Learning: It's Effect on the Retention Rate of Graduate Students. Journal of Education and Practice, 6(14), 1-6.

Simaibang, B. (2011). a Functional Model of Language, Interrelations of Language, Text, and Context, and the Implications for Language Teaching. Jurnal Linguistika, 2(2), 16-28.

Torres, G. (2015). 'Reading' World Link: A Visual Social Semiotic Analysis of an EFL Textbook. International Journal of English Language Education, $\quad 3(1), \quad 239-253$. https://doi.org/10.5296/ijele.v3i1.7200

Van, L. T. (2005). Introducing social semiotics. New York: Routledge.

Weninger, C. (2020). Multimodality in critical language textbook analysis. Language, Culture and Curriculum, $\quad 0(0), \quad 1-14$. https://doi.org/10.1080/07908318.2020.1797083

Weninger, C., \& Kiss, T. (2013). Culture in English as a foreign language (EFL) textbooks: A semiotic approach. TESOL Quarterly, 47(4), 694-716. https://doi.org/10.1002/tesq.87

Yazdanmehr, E., \& Shoghi, S. (2014). Design and application of a "textbook visual effects" evaluation checklist. Theory and Practice in Language Studies, 4(3), 473-480. https://doi.org/10.4304/tpls.4.3.473-480 